\title{
Una propuesta de protección del patrimonio cultural desde la actualización de las policías locales
}

\section{Francisco José Rufián Fernández}

${ }^{a}$ Policía Local; Doctorando en "Derecho, Gobierno y Políticas Públicas” Universidad Autónoma de Madrid, C/ de Kelsen, 1, 28049, Madrid. francisco.rufian@gmail.com.

\begin{abstract}
Resumen
Independientemente de las figuras de protección que apliquemos, o de los organismos involucrados en la defensa del patrimonio, ya sean de nivel estatal o autonómico, la complejidad inherente a la gestión y protección del patrimonio termina siempre siendo una materia que se resuelve a nivel local. La diversidad de disciplinas que de una forma u otra se ven involucradas (patrimonio, medio ambiente, urbanismo...) no hace sino hacer su gestión más compleja, y es el ámbito local el que mejores características posee para pensar nuevas propuestas e ideas. El presente artículo pretende, por tanto, hacer una sucinta presentación del papel que desempeñan en la actualidad los municipios en la protección del patrimonio y, más concretamente, las funciones que podrían desempeñar las policías locales en la mejora de la gestión y la protección del patrimonio cultural.
\end{abstract}

Palabras clave: protección del patrimonio cultural, municipios, policía local.

\begin{abstract}
Regardless of the protection figures that we can apply, or the institutions involved in the heritage's protection, whether they are from the government or the communities, the inherent complexity of heritage management and protection ultimately becomes always a subject solve in the local level. The diversity of disciplines that have been in one way on other involved (heritage, environment, urban planning...) only increase the complexity of management, and the local level is the one which best characteristics to think about new proposals and ideas. The intention in the current paper is to make a presentation about the role of towns in heritage protection, and, more precisely, the tasks that local police could play in improving of heritage management and protection.
\end{abstract}

Keywords: cultural heritage protection, towns, local police. 


\section{Introducción}

Lo principal a la hora de presentar el papel que los municipios desempeñan, o más bien deberían desempeñar, en la protección del patrimonio, es definir los problemas que vienen derivados por la indefinición existente dentro de los diferentes marcos reguladores de la actividad administrativa, que lleva invariablemente a encontrar duplicidades y soluciones de compromiso, que suponen un uso excesivo de recursos que no redundan en beneficio de la sociedad.

Por otro lado, debemos ser conscientes que el papel de los gobiernos locales se ha transformado completamente, sus competencias han crecido constantemente a demanda de los requerimientos de una sociedad que crecía gracias al desarrollo económico y a la globalización. La adaptación de los municipios ha sido, por tanto, obligada para poder garantizar el acceso a medios y recursos a el mayor número de personas posibles. Así, como administraciones públicas más cercanas a los ciudadanos, y donde el ciudadano encuentra la forma más directa de participación en la vida política, y, por ende, económica y social, su papel sigue siendo crucial a la hora de plantear cómo afrontar las crisis económicas, y cómo seguir creciendo en el acceso a los derechos por parte de los ciudadanos. Tanto regiones como corporaciones locales han aumentado su presencia activa como actores importantes en la vida política, social y económica, no sólo aumentando su nivel de competencias en la gestión de políticas públicas, sino que también han incrementado su capacidad política para atender nuevas demandas y de promover nuevas estrategias de cooperación y de desarrollo territorial.

De un modo similar, la realidad de las policías locales en la actualidad es la consecuencia de una adaptación progresiva, como servicio público de primera necesidad, a las demandas que la sociedad ha ido planteando, dentro del contexto aludido anteriormente. La actividad policial necesita de una mayor especialización y sensibilización social para dar respuesta a los continuos desafíos que cada vez, con mayor insistencia se reclaman desde la sociedad. A mayor grado de complejidad de las sociedades y de sus derechos, los cuerpos policiales deben asumir una mayor profesionalización y una continua mejora en sus competencias técnicas para adecuarse a las exigencias que la sociedad demanda. Pero es necesario replantear el rol que las policías locales tienen actualmente dentro del sistema policial español, de modo que estén en condiciones de dar un servicio de calidad a la ciudadanía, ya que existe una disyuntiva entre la demanda social y delictual y la inexistente modificación y actualización de las leyes que organizan el sistema policial español, que como se planteará más adelante, obliga a soluciones de conveniencia a la hora de planificar y ejecutar el trabajo policial.

\section{Normativa sobre la protección del patrimonio cultural y las Entidades Locales}

La normativa que ampara en España la protección del patrimonio histórico, aunque no se pretende entrar a analizar la misma por quedar fuera de las intenciones del presente artículo, emana, como no puede ser de otra manera, de la Constitución. En ella se establece la división competencial entre el Estado y las Comunidades Autónomas, en sus artículos 148.1 .16 y 149.1 .28 , que dicen así:

- 148.1: "Las Comunidades Autónomas podrán asumir competencias en las siguientes materias: 16. Patrimonio monumental de interés de la Comunidad Autónoma".

- 149.1: "El Estado tiene competencia exclusiva sobre las siguientes materias: 28. Defensa del patrimonio cultural, artístico y monumental español contra la exportación y la expoliación".

Surgieron a su tenor, algunas cuestiones a aclarar en base a este reparto competencial que, siguiendo al profesor Alegre Ávila, pueden resumirse en: por un lado, "el alcance que haya de darse a la expresión "interés de la Comunidad Autónoma", como criterio delimitador de su competencia", y por otro, "la necesaria articulación entre ambos artículos, como exigencia derivada de una ordenación integral de la materia" (Alegre, 1994). Es por tanto que, tras el desarrollo de los diferentes estatutos de autonomía, se redacta la Ley del Patrimonio Histórico Español de 25 de junio de 1985 (en adelante LPHE), que recoge textualmente en su exposición de motivos "impuesta por una nueva distribución de competencias entre Estado y Comunidades Autónomas que, en relación a tales bienes, emana de la Constitución y de

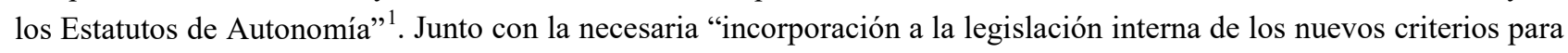

\footnotetext{
${ }^{1}$ Fuente: https://www.boe.es/buscar/act.php?id=BOE-A-1985-12534
} 
la protección y conservación de los bienes históricos y culturales adoptados por los organismos representativos de la comunidad internacional" (Alegre, 2015).

En este sentido debemos recordar que el Tribunal Constitucional, en su STC 17/1991 de 31 de enero ${ }^{2}$, marcó la línea interpretativa a la LPHE que se ha seguido hasta el día de hoy, en la que la mayor parte de las competencias relativas a la protección y conservación del patrimonio cultural, pasan a corresponder a las Comunidades Autónomas, y donde al Estado se le atribuyen las competencias exclusivas en lo referente a la lucha contra la expoliación y la exportación ${ }^{3}$. Pudiendo las referidas Comunidades Autónomas establecer sistemas alternativos o complementarios de protección, así como la declaración de Bienes de Interés Cultural.

Así, las legislaciones propias de las Comunidades Autónomas han ido asumiendo de diferente manera la gestión y la protección del patrimonio histórico, llegando a mejorar aspectos de la LPHE, como por ejemplo las figuras de protección. Pero se puede observar nuevamente la falta de correspondencia entre el ámbito normativo de la Comunidad Autónoma y el ámbito de gestión diaria de los administrados, que lleva a situaciones continuas de desprotección del patrimonio, las cuales podían solucionarse mediante la asunción de medidas de protección más activas por parte de los ayuntamientos. Sirva como ejemplo, que se trae a colación dentro de los múltiples existentes solo por su repercusión mediática, el caso del Eccehomo de Borja (Zaragoza), que no tuvo mayor trascendencia legal debido a no encontrarse bajo la protección de ninguna de las figuras jurídicas recogidas ni en la legislación estatal ni en la legislación aragonesa (Alegre, 2018). Este caso llamó la atención de los medios de comunicación por la simple banalización de su carácter cómico, pero son innumerables los bienes patrimoniales que se pierden cada año por motivos similares y que escapan al conocimiento de las autoridades encargadas de su protección, y es en este ámbito donde los municipios pueden ejercer una labor más activa. Por un lado con nuevas figuras de protección, y por otro, ejerciendo una labor de policía y control administrativo de las intervenciones en bienes culturales, que encajan con otras funciones propias de los municipios como pueden ser las urbanísticas.

En este punto toca analizar cómo quedan los municipios dentro del reparto de competencias y obligaciones referidas a la protección del patrimonio. Ya en la propia Constitución, podemos establecer la base de una obligación legal que vincula la actividad administrativa de los ayuntamientos en la conservación del patrimonio histórico, en tanto que ente administrativo más, dentro de organización administrativa del Estado. El artículo 46 de la Constitución española de $1978^{4}$ señala que los "poderes públicos garantizarán la conservación y promoverán el enriquecimiento del patrimonio histórico, cultural y artístico de los pueblos de España y de los bienes que lo integran...".

Dentro del término "los poderes públicos" se incluye a las Entidades locales y específicamente a los Ayuntamientos. Esta expresión "los poderes públicos" debe entenderse dentro de la concepción descentralizada del estado que los artículos 2 y 137 de la Constitución determinan, y son por tanto extensibles a todos los Entes de titularidad pública y como no puede ser de otra manera, también al "poder municipal" (García, 2004). Por tanto el mandato del artículo 46 de la Constitución vincula la actividad de los Ayuntamientos, pero eso sí, reservando su concreción y límites a lo que dispongan las leyes ${ }^{5}$. En este sentido las competencias municipales deben entenderse dentro de lo que García Rubio, siguiendo a Morell Ocaña denomina "un régimen jurídico bifronte" (García, 2004), es decir su concreción competencial dependerá, tanto de la legislación estatal como de la autonómica.

Así los dos títulos competenciales directos que afectan a las Entidades Locales son las leyes autonómicas, que por su extensión quedarán fuera del análisis de este artículo, y la LPHE, que en su artículo 7, establece, "los Ayuntamientos

\footnotetext{
${ }^{2}$ Fuente: https://tc.vlex.es/vid/149-28-an-12-13-26-53-15356795

${ }^{3}$ Es extensible esta competencia al ámbito penal, propio del Estado, y a lo que la propia ley denomina "interés general”.

${ }^{4}$ Fuente: https://www.boe.es/buscar/act.php?id=BOE-A-1978-31229

${ }^{5}$ En referencia a los principios rectores de la política social y económica (Capítulo III del Título I) establece el artículo 53 "informarán la legislación positiva, la práctica judicial y la actuación de los poderes públicos", y "sólo podrán ser alegados ante la jurisdicción ordinaria de acuerdo con lo que dispongan las leyes que los desarrollen". En esta línea, el Tribunal Constitucional ha tenido ocasión de señalar (STC 80/1982, de 20 de diciembre) que "el valor normativo inmediato de los artículos 39 a 52 de la Constitución ha de ser modulado en los términos del artículo 53.3 de la Norma Fundamental", precepto que "impide considerarlos normas sin contenido, obligando a los poderes públicos a tenerlos presentes en la interpretación tanto de las restantes normas constitucionales como de las leyes" (SSTC 19/1982, de 5 de mayo y 14/1992, de 10 de febrero, entre otras). Fuente: https://app.congreso.es/consti/constitucion/indice/sinopsis/sinopsis.jsp? art=53\&tipo=2
} 
cooperarán con los Organismos competentes para la ejecución de esta Ley en la conservación y custodia del Patrimonio Histórico Español comprendido en su término municipal, adoptando las medidas oportunas para evitar su deterioro, pérdida o destrucción. Notificarán a la Administración competente cualquier amenaza, daño o perturbación de su función social que tales bienes sufran, así como las dificultades y necesidades que tengan para el cuidado de estos bienes. Ejercerán asimismo las demás funciones que tengan expresamente atribuidas en virtud de esta Ley”.

Asigna de ese modo la LPHE un carácter cooperador a los Ayuntamientos, dotándoles de una serie de competencias que tienen una relación directa con el entorno en el que se encuentran los bienes, así podemos mencionar la elaboración de planes urbanísticos, la ejecución de obras, la otorgación de licencias, la disciplina urbanística o la declaración de ruina. Tal como Alegre Ávila explica, "con independencia de las concretas funciones y deberes que la LPHE asigna a los mismos, las "medidas oportunas" a que se refiere el art. 7 LPHE que deberán adoptar los Ayuntamientos para evitar el deterioro, pérdida o destrucción del patrimonio radicado en el término municipal, son básicamente las que en el ámbito de sus competencias en materia urbanística pueden disponer a fin de proteger y conservar el patrimonio inmobiliario sito en el correspondiente término municipal"(Alegre, 1994). Enlazándose de esta manera todo otro marco competencial que capacita a los ayuntamientos para que, de manera directa o indirecta, puedan promover la protección del patrimonio, como así estipula la Ley de Bases de Régimen Local de $1985^{6}$, a lo largo de varios puntos de su artículo 25 :

1. El Municipio, para la gestión de sus intereses y en el ámbito de sus competencias, puede promover actividades y prestar los servicios públicos que contribuyan a satisfacer las necesidades y aspiraciones de la comunidad vecinal en los términos previstos en este artículo.

2. El Municipio ejercerá en todo caso como competencias propias, en los términos de la legislación del Estado y de las Comunidades Autónomas, en las siguientes materias:

- Urbanismo: planeamiento, gestión, ejecución y disciplina urbanística. Protección y gestión del Patrimonio histórico. Promoción y gestión de la vivienda de protección pública con criterios de sostenibilidad financiera. Conservación y rehabilitación de la edificación.

- Medio ambiente urbano: en particular, parques y jardines públicos, gestión de los residuos sólidos urbanos y protección contra la contaminación acústica, lumínica y atmosférica en las zonas urbanas.

- Policía local, protección civil, prevención y extinción de incendios.

- Información y promoción de la actividad turística de interés y ámbito local.

3. Las competencias municipales en las materias enunciadas en este artículo se determinarán por Ley debiendo evaluar la conveniencia de la implantación de servicios locales conforme a los principios de descentralización, eficiencia, estabilidad y sostenibilidad financiera.

Todo este abanico competencial, que de una forma u otra puede aportar una amplia capacidad a las Entidades Locales a la hora de gestionar el patrimonio, toma su forma jurídica a través de la potestad reglamentaria de dichas entidades, y por tanto está supeditada al principio de legalidad, en referencia siempre a las diversas legislaciones estatales y autonómicas que pueden tener incidencia en la materia.

Sin duda, el campo en el que los ayuntamientos encuentran un mayor ámbito de actuación es el de la normativa urbanística, siguiendo el análisis que realiza la Federación Española de Municipios y Provincias, en el documento titulado "Gestión municipal del patrimonio histórico-cultural"7, podemos observar que la normativa urbanística posibilita el uso de los Catálogos, como técnica urbanística que viene determinada por las propias condiciones del planeamiento urbanístico, y que contribuye de forma singular a la protección tanto cultural como ambiental. Su objetivo no es otro que la protección y conservación, y por lo general, los catálogos urbanísticos conciernen a los edificios, pero también existen de otros tipos, como pueden ser los de protección arqueológica, los etnológicos, o los de bienes concretos característicos de la zona.

\footnotetext{
${ }^{6}$ Articulado tras la reforma efectuada por la Ley 27/2013, de 27 de diciembre, de racionalización y sostenibilidad de la Administración Local. Fuente: https://www.boe.es/buscar/pdf/2013/BOE-A-2013-13756-consolidado.pdf

${ }^{7}$ Disponible en: http://femp.femp.es/files/566-1683-archivo/Recomedaciones_Plan_Gestion_Municipal_PHC.pdf
} 
Por otro lado, y contando con los instrumentos de los que dota la normativa urbanística a los ayuntamientos, se puede garantizar una tutela y control de las intervenciones, que como exige la propia LPHE debe ser realizado por profesionales cualificados y dentro del estricto cumplimiento de la normativa existente. En este punto es importante destacar la necesaria cooperación entre las distintas administraciones, sobre todo en todos aquellos lugares sin planeamiento específico, y por tanto dependientes de las Diputaciones Provinciales y de las Comunidades Autónomas. Todos los inventarios y registros deberían formar parte de la documentación existente en los Ayuntamientos, por pequeños que éstos sean; esto es fundamental, por ejemplo, en la protección del patrimonio arqueológico ${ }^{8}$. De este modo, los planes urbanísticos, en conjunto con las ordenanzas reguladoras pueden establecer modelos de protección muy eficaces y que enlazan perfectamente con el ejercicio de las funciones administrativas de los ayuntamientos.

Pero para poder ejercer la misión de proteger y conservar el patrimonio, y para realizarlo de manera efectiva, es necesaria la colaboración con los servicios técnicos de la comunidad autónoma, o con el Estado según el bien patrimonial del que se trate. En la práctica esta colaboración suele llevarse a cabo a través de las Comisiones Locales o Provinciales, pero, en los casos en los que el bien no se encuentra dentro de las categorías de protección previstas, o el municipio no es considerado conjunto histórico, o similar, todo el procedimiento de autorización administrativa se sustancia dentro del propio ayuntamiento. Esto nos lleva a que los municipios tienen una gran responsabilidad en la protección, la conservación y la gestión del patrimonio, pues intervienen de una forma u otra en los bienes o en su entorno directa o indirectamente.

En resumen, como hemos apuntado someramente, y siguiendo a Ana Yañez, la vinculación del patrimonio "con otros ámbitos sectoriales como el urbanismo, la ordenación territorial y la gestión medioambiental, entre otros, permite establecer conexiones y paralelismos que enriquecen su estudio y posibilita abrir nuevos campos de investigación" (Yañez, 2018).

\section{Organización policial y la protección del patrimonio}

El sistema policial español, se ha configurado siguiendo la misma estructura normativa que el resto de leyes, así, es en el texto constitucional, en su artículo 104, donde se establece la misión de los cuerpos policiales como integrantes del poder ejecutivo, y se determina que su organización, competencias y régimen jurídico, se realizará por mandato constitucional a través de una ley orgánica, en este caso, la Ley Orgánica 2/1986, de 13 de marzo, de Fuerzas y Cuerpos de Seguridad (en adelante LOFCS).

Es en la misma LOFCS, donde se encomiendan las competencias y la distribución territorial de cada uno de los cuerpos policiales, no haciéndose mención expresa a las competencias en patrimonio. Dentro de las funciones que se otorgan a las Policías Locales en esta Ley encontramos, artículo 53.1:

- Policía Administrativa, en lo relativo a las Ordenanzas, Bandos y demás disposiciones municipales dentro del ámbito de su competencia.

- Participar en las funciones de Policía Judicial, en la forma establecida en el artículo 29.2 de esta Ley. (carácter colaborador).

- Efectuar diligencias de prevención y cuantas actuaciones tiendan a evitar la comisión de actos delictivos en el marco de colaboración establecido en las Juntas de Seguridad.

Pero, la configuración de las competencias de las policías locales se continúa desarrollando normativamente al amparo competencial del artículo 148.1.22 de la Constitución Española que otorga a las Comunidades Autónomas las competencias en coordinación de las Policías Locales en su territorio y demás facultades, las cuales quedan establecidas en el artículo 39 de la $\operatorname{LFCS}^{9}$ mandato que se refleja igualmente en los diferentes Estatutos de Autonomía. De ese modo se establecen por las diferentes Comunidades Autónomas leyes de coordinación de policías locales, en las que, en base

\footnotetext{
${ }^{8}$ Ibidem.

${ }^{9}$ Corresponde a las Comunidades Autónomas, de conformidad con la presente Ley y con la de Bases de Régimen Local, coordinar la actuación de las Policías Locales en el ámbito territorial de la Comunidad.
} 
a una realidad social más actualizada, se amplían en algunos casos las competencias marcadas por la LOFCS, reflejando unas competencias algo más cercanas a la práctica diaria de las policías locales. Así, y poniendo como ejemplo la Ley 1/2018 de 22 de febrero, de Coordinación de Policías Locales de la CAM, estas funciones quedan reflejadas en su artículo 11 de la siguiente manera:

- Ejercer la policía administrativa en relación con el cumplimiento de las ordenanzas, bandos y demás disposiciones municipales, así como de otras normas autonómicas y estatales, dentro del ámbito de sus competencias.

- Velar por el cumplimiento de las disposiciones dictadas en materia de protección del medio ambiente cuando las funciones de vigilancia sean competencia municipal, bien originaria o delegada.

- Efectuar las diligencias de prevención y cuantas actuaciones tiendan a evitar la comisión de actos delictivos o su comprobación.

- Además de las funciones establecidas en los puntos anteriores, en virtud de convenio entre la Comunidad de Madrid y los ayuntamientos, los Cuerpos de policía local podrán ejercer en su término municipal las siguientes funciones:

$1^{\mathrm{o}}$ Velar por el cumplimiento de las disposiciones y órdenes singulares dictadas por los órganos administrativos de la Comunidad de Madrid.

$2^{\circ}$ Inspeccionar las actividades sometidas a la ordenación o disciplina de la Comunidad de Madrid, denunciando toda actividad ilícita.

$3^{\circ}$ Adoptar las medidas necesarias en orden a garantizar la ejecución forzosa de los actos o disposiciones de la Comunidad de Madrid.

En este punto es conveniente hacer referencia a la Ley de Bases de Régimen Local, que como se mencionó en el capítulo anterior, determina el carácter dependiente de las policías locales con respecto a sus propios ayuntamientos.

En definitiva, el sistema policial español es un reflejo de la actividad política y administrativa, siendo un servicio público cuya principal razón de ser se manifiesta en la regulación y control de las diferentes actividades que se pueden desarrollar por una administración pública. De este modo, podemos dividir la actividad policial en dos grandes líneas, por un lado, la administrativa, y por otro la de seguridad. No es intención de este artículo analizar las competencias en seguridad de las policías locales, si al contrario sus competencias administrativas, en las que se basa la propuesta de este artículo, al entender que por la propia división competencial y despliegue territorial, son las Fuerzas y Cuerpos de Seguridad del Estado (Policía Nacional y Guardia Civil), las que ostentan el mayor número de competencias relativas a la prevención y represión del delito, mientras que las policías locales están orientadas a una función más cercana a la de policía administrativa, pero acorde con su evolución, y con el crecimiento de los núcleos urbanos, se ha propiciado la asunción de funciones que estarían en principio reservadas a otros cuerpos policiales (Acosta, 2015), dando respuesta así a las nuevas necesidades inherentes a esos cambios.

Por otro lado, es necesario hacer mención, aunque sea de forma sucinta, a las funciones de policía judicial, que otorga el artículo 126 de la Constitución: "La policía judicial depende de los Jueces, de los Tribunales y del Ministerio Fiscal en sus funciones de averiguación del delito y descubrimiento y aseguramiento del delincuente, en los términos que la ley establezca." Estableciendo la base en la que se fundamentan, junto con el artículo 283 de la Ley de Enjuiciamiento Criminal, los integrantes de la conocida como policía judicial "genérica", que no son sino diferente personal perteneciente a la administración que por sus propias competencias venían realizando estas funciones en el momento de publicación de la ley (Pomares y Vadillo, 2017).

Estas funciones debemos entenderlas en la línea que ha marcado el Tribunal Constitucional en "las SSTC 197/1983; 201/1989; 138/1992; 303/1993, referidas al material probatorio aportado por las policías judiciales en los procesos penales. En estas sentencias se matiza la dicción del artículo 126 de la Constitución sobre las funciones encomendadas a la Policía Judicial al establecer que, a ésta, más que a realizar los actos de prueba, lo que en realidad le encomienda la Norma Fundamental es la realización de los actos de investigación pertinentes para acreditar el hecho 
punible y la autoría. No obstante, esta actividad investigadora también le habilita a asumir una función aseguradora del cuerpo del delito, así como a acreditar su preexistencia mediante los pertinentes actos de constancia, sin por ello contradecir lo dispuesto en la Constitución."10

Dentro de estos colectivos se encuentran los cuerpos de policía local, o los agentes forestales, cuyo trabajo en todo lo referente a la protección penal y administrativa del patrimonio se encuentra actualmente en una etapa muy inicial en España. Como ejemplo de las iniciativas que conjugan la parte administrativa con la penal, y que por su trayectoria y similitudes puede servir de apoyo a las propuestas de este artículo, encontramos el trabajo que desempeña el Cuerpo de Agentes Rurales en Cataluña, el cual, desde el año 2012, momento en el que firmaron un convenio de colaboración con la Dirección General de Patrimonio Cultural, vienen trabajando de una forma muy acertada en la protección el patrimonio (Picón, 2018).

Son muchas las similitudes que se encuentran entre la regulación y el tratamiento jurídico del patrimonio cultural y el medio ambiente, como reflejo de una legislación que ha evolucionado en respuesta de las demandas de una sociedad cada vez más concienciada con ambas problemáticas. A esto hay que añadir también, similitudes existentes en su propia conceptualización, llegando algunos autores a afirmar que "se construye el concepto de medio ambiente para relacionarnos con el medio físico y definirlo" (Ariño, 2010).

Por eso es común que la organización policial haya tendido a unificar en unidades especializadas las competencias medioambientales y las de patrimonio histórico, por ejemplo, el Seprona en la Guardia Civil, o las diferentes Unidades de Medio Ambiente de las policías locales. Del mismo modo las propias fiscalías especializadas ${ }^{11}$, al ser las competentes en los delitos relacionados con medio ambiente y el urbanismo, extienden su competencia a los delitos contra el patrimonio histórico. Aunque todavía es largo el recorrido para poder tratar adecuadamente la interrelación entre el patrimonio natural y el patrimonio histórico, ya que sobre todo en el ámbito municipal, comparten espacios como los parques históricos, donde se entremezclan de forma tal, que su gestión debería singularizarse para poder preservar esos valores de forma correcta.

Siguiendo con la organización policial en España, la Policía Nacional y Guardia Civil, son los dos cuerpos que ostentan directamente las competencias relacionadas con el patrimonio histórico, a través de sus unidades especializadas (también lo ostentan las policías autonómicas pero ese ámbito queda fuera del objeto del presente trabajo). Es con la aparición de la Ley de Patrimonio Histórico Español de 1985 y más concretamente con el Real Decreto 111/1986, de desarrollo de la ley, cuando se crea la Brigada de Protección del Patrimonio Histórico de la Policía Nacional, a través de su Disposición Adicional Primera, posteriormente modificada por el Real Decreto 64/1994 de desarrollo parcial de dicha ley, con el que se incluye el Grupo de Patrimonio de la Unidad Central Operativa del Servicio de Policía Judicial de la Guardia Civil, conformándose ambos como los cuerpos policiales que reciben una competencia directa por la LPHE para "la investigación y persecución de las infracciones que contra ésta se realicen" 12 .

Como es lógico, la normativa estatal otorga las competencias de protección a los cuerpos de seguridad estatales, pero cuando se van elaborando las diferentes normativas de protección autonómica, recordemos que son las que tienen mayor peso en la protección del patrimonio, esta competencia vuelve a recaer en los mismos cuerpos policiales, seguramente debido a ser los únicos que cuentan con personal especializado. Obviamente, las Comunidades Autónomas con cuerpos de policía propio, crean unidades similares de protección del patrimonio. Pero, en lo referente a las policías locales, no se les ha otorgado una competencia directa en materia de patrimonio, aunque en la práctica, han venido trabajando en este ámbito, tanto por la aplicación de las leyes autonómicas, como de la diferente normativa municipal ${ }^{13}$ empujados por el hecho de su mayor cercanía al ciudadano y mayor presencia en los municipios.

Como se ha visto anteriormente, dentro de la gestión municipal del patrimonio, convergen diferentes áreas, como son medio ambiente, cultura, urbanismo, etc. que en algunas ocasiones hace complejo el trabajo, sobre todo en materia de

\footnotetext{
${ }^{10}$ Texto extraído de: https://app.congreso.es/consti/constitucion/indice/sinopsis/sinopsis.jsp?art=126\&tipo=2

${ }^{11}$ Creadas a partir de la Instrucción 11/2005, sobre la Instrumentalización Efectiva del Principio de Unidad de Actuación Establecido en el Artículo

124 de la Constitución Española.

${ }^{12}$ Fuente: https://www.boe.es/buscar/act.php?id=BOE-A-1986-2277\&b=92\&tn=1\&p=19940302\#primera

${ }^{13}$ Recodemos que esta normativa si otorga competencia directa, pero no se ha visto desarrollada en unidades o servicios especializados.
} 
inspecciones y control. Es aquí, donde los cuerpos de policía local, al estar dotados de competencias transversales, pueden ejercer un amplio de actividades, al ser un colectivo que posee una gran potencialidad en la protección del patrimonio, ya que sus características les permiten actuar tanto de manera reactiva, como preventiva, anteponiéndose a los posibles daños mediante inspecciones o colaboraciones con organismos de los diferentes ámbitos relacionados. Una vez detectado el daño se puede actuar tanto desde el campo administrativo como judicial, según nos encontremos con una infracción o delito. Cuentan, además, por su idiosincrasia propia, con el conocimiento de la normativa autonómica y local, necesaria para poder actuar en materia de patrimonio histórico, y con un ámbito territorial de actuación circunscrito al municipio, de ese modo se puede cubrir un amplio abanico de posibilidades, que es imposible cubrir desde las unidades especializadas de Policía Nacional y de Guardia Civil.

En resumen (Fig. 1), la actividad policial debe adaptarse a las demandas de la sociedad, y a la evolución de las formas de vida en las ciudades mediante una mayor especialización. Es por esto, que las policías locales, por su cercanía han ido aumentando en la práctica sus ámbitos competenciales, y así sucede actualmente en el campo de la protección del patrimonio, donde las policías locales vienen realizando diferentes servicios relacionados, por demanda social, pero es necesario seguir trabajando en una formación específica (imprescindible en cualquier especialización) que permita cubrir de una forma efectiva un ámbito competencial que le es propio.

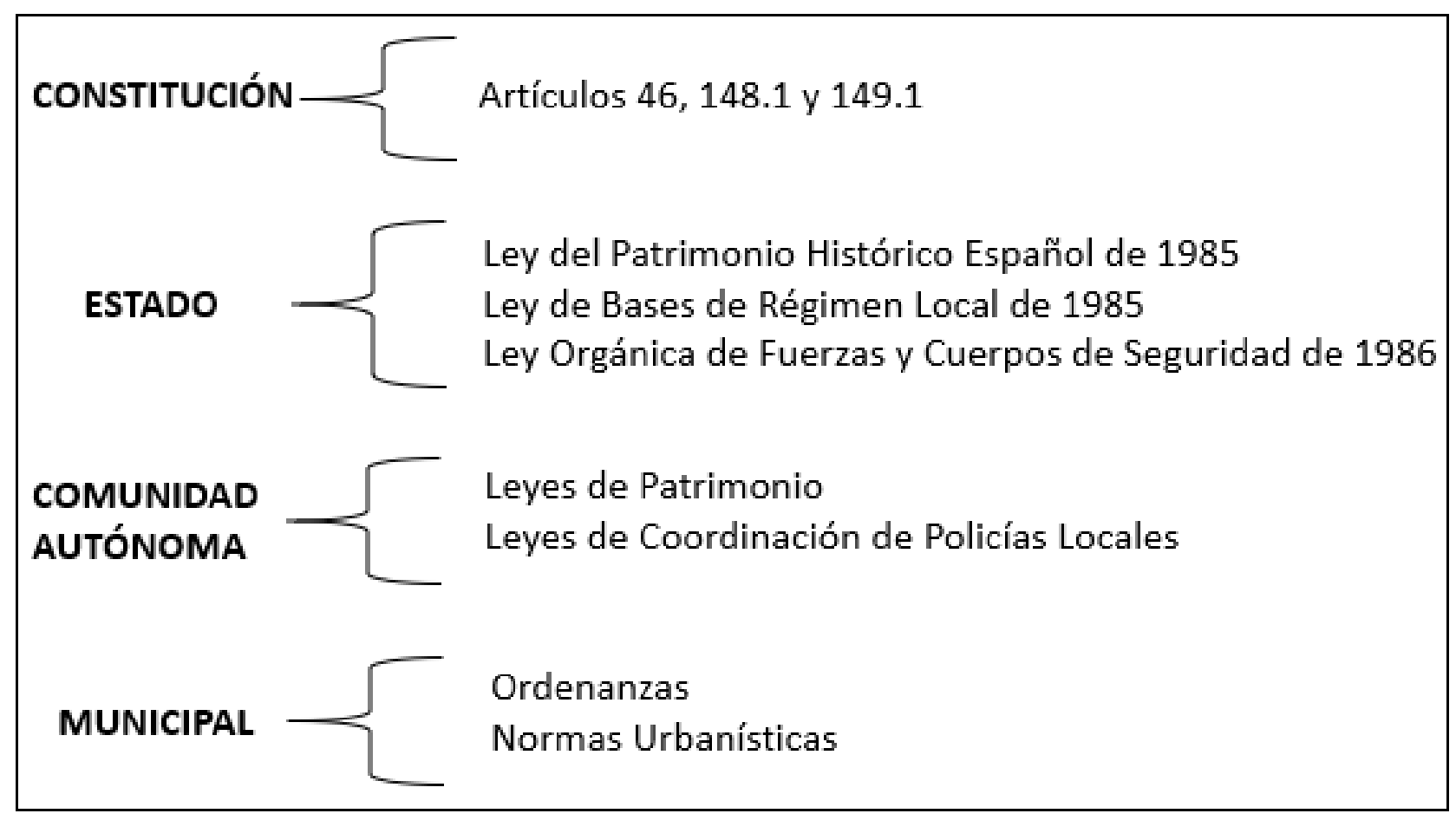

Fig. 1 Esquema de la normativa mencionada

\section{Conclusiones y propuestas}

Como se ha visto a lo largo del artículo, la transversalidad competencial ${ }^{14}$ y la capacidad de actuar en diversos ámbitos que afectan al patrimonio, por parte de las policías locales, genera un amplio abanico de posibilidades para los ayuntamientos. Quizá las más importantes puedan ser las labores preventivas, porque, ejerciendo la inspección y control de las actividades susceptibles de afectar al patrimonio, se garantiza de una forma efectiva su protección, como se ha podido comprobar en los últimos años en materias afines como el medio ambiente. Todo en conjunción con la posibilidad de actuar igualmente de forma reactiva, ya que, por distribución territorial, la policía local suele ser el

\footnotetext{
${ }^{14}$ Además de encontrarse bajo la normativa estatal, autonómica y municipal, en el ámbito de sus competencias.
} 
primer actuante, y una vez detectado un daño, puede por tanto ejercer las medidas oportunas para que se aplique la normativa administrativa, en caso de infracción, o medidas judiciales en caso de delito.

Todo esto quedaría a medias si no se garantiza la colaboración entre las diferentes administraciones involucradas, ya que como apunta Javier Bermúdez Sánchez, "la complejidad de la gestión del patrimonio histórico y cultural se suele poner de manifiesto en el ámbito local” pero es "hasta el ámbito autonómico y estatal, donde sin duda hay que acudir para su resolución” (Bermúdez, 2019). En este punto cabría mencionar la necesaria colaboración en el diseño e implementación de planes de protección y de emergencias en edificios patrimoniales.

En resumen, los cuerpos de policía local por su ámbito de actuación y amplio abanico de competencias se conforman como un cuerpo con un gran potencial a la hora de prevenir y actuar en la protección del patrimonio cultural en todas sus variantes. Aunque es mucho el trabajo que queda por hacer, se debe:

- Fomentar la formación específica para poder actuar en las diferentes áreas de protección del patrimonio. Este punto es básico para que los agentes tengan recursos para afrontar las actuaciones y que éstas se hagan siguiendo unos criterios comunes que garanticen la seguridad jurídica.

- Crear procedimientos de actuación y de colaboración con las diferentes administraciones relacionadas con la gestión del patrimonio.

- Formalizar convenios de colaboración con los grupos especializados tanto de Policía Nacional como Guardia Civil, que permita sumar esfuerzos y garantizar un servicio adecuado.

- Creación de unidades o servicios especializados en aquellos municipios donde sea aconsejable por el alto número de bienes patrimoniales o por el grado de incidencias delictuales.

- Aprovechar estas unidades y la cercanía a los vecinos de las policías locales para concienciar sobre el valor que el patrimonio aporta a la ciudad y a las personas.

\section{Referencias}

Acosta, P. (2015). Seguridad pública en el ámbito local. En F. García Rubio (Dir.), Análisis de las repercusiones de la reforma local sobre la organización, competencias, y servicio de las entidades locales (pp. 299-320). Madrid: Instituto Nacional de Administración Pública.

Alegre, J. M. (2018). Del Eccehomo de Borja al San Jorge de San Miguel de Estella, la debida regulación de la profesión de Conservador-Restaurador. En A. Galán Pérez y D. Pardo San Gil (Coords.), Las profesiones del Patrimonio Cultural. Competencias, formación y trasferencia del conocimiento: reflexiones y retos en el Año Europeo del Patrimonio Cultural 2018 (pp. 407-410). Albacete: ACRE y GE-IIC Editores.

Alegre, J. M. (2015). El patrimonio histórico español: régimen jurídico de la propiedad histórica. Anuario de la Facultad de Derecho de la UAM, 19, 213-251.

Alegre, J. M. (1994). Evolución y régimen jurídico del Patrimonio Histórico: la configuración dogmática de la propiedad histórica en la Ley 16/1985, de 25 de junio, del Patrimonio Histórico Español. Colección Análisis y documentos, 5. Madrid: Ministerio de Cultura, Secretaría General Técnica.

Ariño, A. (2010). La patrimonialización de la cultura y sus paradojas postmodernas. En D. Porporato (Ed.), Nuove pratiche di comunità. I patrimoni culturali etnantropologici fra tradizione e complesità sociale (pp. 15- 32). Torino, Italia: Omega Edizioni.

Bermúdez, J. (2019). Derecho del patrimonio histórico y cultural. Gestión estatal, autonómica y local. Granada, España: CEMCI Publicaciones.

García, F. (2007). El papel de los Ayuntamientos en la Conservación del patrimonio cultural. Estado de la cuestión. En F. García Rubio, E. Sánchez Goyanes y F. Javier Melgosa (Eds.), Régimen jurídico de los centros históricos (pp. 90-118). Madrid: Editorial Dykinson.

Picón, A. (2018). Expolio arqueológico en Cataluña y la implicación del Cos D’Agents Rurals de la Generalitat de Cataluya. En A. Yañez y I. Rodríguez Temiño (Eds.), El Expoliar se va a acabar. Uso de detectores de metales y arqueología: sanciones administrativas y penales (pp. 103-129). Valencia: Editorial Tirant lo Blanc. 
Una propuesta de protección del patrimonio cultural desde la actualización de las policías locales

Pomares, C., y Vadillo, J. (2017). La policía local como policía judicial. Manual para la inspección ocular técnico-policial. Alicante: Editorial Club Universitario.

Yañez, A. (2018) Patrimonio arqueológico y derecho sancionador. Valencia: Editorial Tirant lo Blanch. 